\title{
CIDADE, NATUREZA E URBANIZAÇÃO: PROPOSIÇÕES PARA UMA HISTÓRIA AMBIENTAL DA REGIÃO METROPOLITANA DE PORTO ALEGRE/RS*
}

\author{
City, nature and urbanization: \\ propositions for an environmental history from the \\ Metropolitan Region of Porto Alegre/RS
}

\author{
Danielle Heberle Viegas ${ }^{1}$ \\ Eduardo Relly ${ }^{2}$ \\ Cleusa Maria Gomes Graebin ${ }^{3}$
}

\begin{abstract}
RESUMO
O estudo proposto é uma tentativa de pensar a história de cidades da Região Metropolitana de Porto Alegre (RMPA) por meio das ferramentas analíticas e conceituais da subdisciplina história ambiental. As cidades da RMPA formaram-se a partir de loteamentos de terras que avançaram sobre microrregiões ambientais sensíveis, tais como várzeas de rios e de riachos, capões de mato e sistemas de banhados largamente associados aos abrangentes sistemas hídricos regionais. $\mathrm{O}$ assentamento nestas áreas se caracterizou pela chegada maciça (em termos demográficos e em curto prazo) de grupos sociais étnico e profissionalmente diversos; além disso, a intensa migração e as políticas desenvolvimentistas de industrialização e promoção urbanística sem regulação ocasionaram problemas ambientais relevantes, não totalmente avaliados. Até o presente momento, tais
\end{abstract}

\footnotetext{
" O presente artigo apresenta resultados de pesquisas de Doutoramento desenvolvidas com apoio do CAPES/ DAAD (processo n. ${ }^{\circ}$ 9457-14-3, 2014) e do CNPq (processo n. ${ }^{\circ} 140316 / 2012$ )

1 É professora do Cursos de História (Bacharelado e Licenciatura) e Arquitetura e Urbanismo (Bacharelado) do Unilasalle. E-mail: danielle.viegas@unilasalle.edu.br. ORCID: https://orcid.org/0000-0003-4299-822X 2 É pós-doutorando em História pela Unisinos e doutor em História pela Freie Universität Berlin (FU BERLIN). E-mail: rellyeduardo@gmail.com. ORCID: https://orcid.org/0000-0001-5196-7332

3 Professora e Coordenadora Adjunta do programa de Pós-Graduação em Memória Social e Bens Culturais (Unilasalle); Professora dos Cursos de História e Arquitetura e Urbanismo (Unilasalle). E-mail: cleusa. graebin@unilasalle.edu.br. ORCID: https://orcid.org/0000-0002-2919-5687
} 
cidades são negligenciadas por profissionais de história ambiental, embora tenham sido alvo de inúmeros estudos relativos à história do planejamento urbano, da história social do trabalho e da constituição de identidades e da memória social. Nossa intenção é, então, esboçar uma agenda de pesquisas para a RMPA focando, especificamente, no exemplo de Canoas/RS. As fontes utilizadas são multivariadas, obedecendo à amplidão das questões ambientais subjacentes ao crescimento da malha urbana citadina. Fotografias, cartografia, documentação administrativa e expressões das memórias dos moradores baseiam a pesquisa.

Palavras-chave: História Ambiental; Região Metropolitana de Porto Alegre; Urbanização.

\begin{abstract}
The following paper is an attempt to think over the history of the cities which form the "Região Metropolitana de Porto Alegre (RMPA)" through the analytical and conceptual tools of environmental history. The RMPA cities have originated from the distribution of plots of land that gradually covered sensitive environmental microregions, such as river and stream floodplains, small forests (capões), and swamps largely connected to the regional widener riverine systems. The settlement in these areas characterized itself by the intensive arrival (in demographic and chronologic terms) of social groups which were ethnic- and professionally diverse; also, the intense migration and policies of urbanistic development caused relevant environmental problems not evaluated yet. Up to now, such cities have been neglected by scholars from the environmental history tradition, though they have been targets of several investigations concerning the history of urban planning, social history, history of local identities, and social memory. Our intention is thus to draw an agenda of environmental history-based research for the RMPA, focusing on the city of Canoas. The sources are varied, and they are the consequence of the widening of environmental questions related to the growth of the city area; pictures, maps, administrative documentation, and even expressions of local social memory will guide this investigation.
\end{abstract}

Keywords: Environmental history; Porto Alegre Metropolitan Area; Urbanization.

\title{
Introdução
}

Notoriamente identificadas a partir de alcunhas tais como cidades dormitório, cidades-industriais e cidades-operárias, localidades associadas às regiões metropolitanas brasileiras são comumente estereotipadas por 
parcela da literatura acadêmica como aglomerações urbanas desprovidas de planejamento. No caso da Região Metropolitana de Porto Alegre/RMPA, costuma-se desconsiderar a formação histórica das cidades, assim como se menospreza uma leitura de seu desenvolvimento, do ponto de vista socioambiental ${ }^{4}$.

Um exemplo disso é o município de Canoas/RS, com uma população estimada de 346.616 habitantes $^{5}$, distribuídos pelos seus 16 bairros. O município, que na década de 1950 teve um aumento populacional de 390\%, ocupa, atualmente, a quarta posição dentre aqueles mais populosos do Rio Grande do Sul. Enquanto um espaço de transformações desenvolvimentistas radicais, a cidade abriga os problemas urbanos clássicos da América Latina: desigualdade territorial e fardo de problemas ambientais sobre os pobres, migrantes e mulheres; uma socialmente acalorada expansão urbana baseada em especulação financeiro-imobiliária, apossamentos, ocupações e despejos violentos. Tais violências contra as pessoas correspondem, não raro, a violações à qualidade de seu meio ambiente (SEDREZ, 2013, p. 61-64). Justifica-se a escolha por Canoas, nesse sentido, como um "caso exemplar" (CALABI, 2012) no contexto da "cadeia de disseminação" (FELDMAN, 2005 , p. 277) de ideias, práticas e modelos que marcaram o fenômeno metropolitano no Brasil.

Tendo em vista a lacuna de análise histórico-ambiental deste município e da região em que ela se insere, intencionamos lançar uma agenda de estudos. A proposta oferece muitos desafios; isto porque o município enfrentou profundas modificações no último século. De espaço de pecuária bovina - herança do período colonial -, cuja divisão social do solo era caracterizada por grandes sesmarias, teve o seu território recortado em lotes nas últimas décadas do século XIX, muitos voltados à prática da orizicultura e à produção de hortifrutigranjeiros.

A mudança paisagística mais expressiva se deu, entretanto, no intervalo entre as décadas de 1930 e 1960. Em apenas trintas anos, Canoas deixou de ser um território de lazer e vilegiatura para dar lugar

\footnotetext{
4 Sobre a RMPA (que, em 2019, abrange 34 municípios) há o predomínio de estudos estatísticos e/ou econômicos (ALONSO, 2001) bem como abordagens voltadas às formas de governança na região (CARRION, 1989; TATSCH, 1990; MARTINS, 1992), em detrimento a outros tópicos, como o seu planejamento urbano e ambiental.

5 IBGE. Canoas, 2019. Disponível em https://cidades.ibge.gov.br/brasil/rs/canoas/panorama. Acesso em 20 ago. 2019.
} 
às indústrias de transformação, desenhando sua peculiaridade no quadro de expressão territorial do projeto desenvolvimentista brasileiro. Este assumiu cores próprias - notoriamente sob argumentos nacionalistas quando comparado com outras políticas desenvolvimentistas aplicadas nas zonas recém-descolonizadas da África e da Ásia e nas demais nações socialistas; de toda a forma, projetos de inserção de áreas marginais marcaram o desenvolvimentismo no Brasil, na esteira da produção industrial e agropecuária desprovidos de limites de ordem natural e social, respaldados por medidas de aceleração do crescimento econômico. Arrefecida a partir da década de 1980 pelos esforços ambientalistas e pela evidência flagrante dos seus excessos no quadrante norte do país, a variante da economia do desenvolvimento brasileira perdeu fôlego juntamente com a democratização do país (ACKER, 2017, p. 6-10).

No Rio Grande do Sul, as dinâmicas industriais "provocaram um impacto na organização dos espaços locais e regionais, uma vez que a implantação das infraestruturas desenhou um novo mapa das redes técnicas do Estado" (UEDA, 2007, p. 169). Às vésperas da década de 1970, as características da metropolização ficaram definitivamente estabelecidas em Porto Alegre (marca de 1 milhão de habitantes, conurbação territorial, fluxo de mobilidade). A institucionalização da Região Metropolitana de Porto Alegre em $1973^{6}$ foi o epicentro desse processo, visto que no decorrer dos decênios de 1950 e 1960, o Estado esteve alinhado com os índices de aumento populacional dos centros urbanos do país, sendo Porto Alegre referida como o "maior agrupamento humano entre São Paulo e Buenos Aires" (SOUZA, 2014, p. 232). Entre as consequências imediatas, ocorreu a polarização da capital como centro urbano e econômico do estado, devido à sua base industrial e à sua capacidade de absorção de mão de obra, bem como à ascensão de políticas públicas voltadas ao gerenciamento da questão metropolitana.

As cidades pertencentes às regiões metropolitanas brasileiras transformaram-se, assim, em um dos alvos das ações de planejamento estatal que, de acordo com Déak (1999, p. 19), se afirmou como uma

6 A região foi oficializada contando com uma população de aproximadamente 1,5 milhões de habitantes, que correspondia a $23 \%$ da população do Estado, distribuída em 14 municípios que perfaziam $3.740,9 \mathrm{~km}^{2}$ de área. A RMPA, em sua designação original, envolvia treze municípios, além da capital: Canoas, Esteio, Sapucaia do Sul, São Leopoldo, Novo Hamburgo, Sapiranga, Campo Bom, Estância Velha, Gravataí, Guaíba, Cachoeirinha, Alvorada e Viamão. 
atividade governamental para regular o ritmo explosivo de urbanização. Com efeito, o valor econômico das áreas urbanas transcendeu os interesses municipais, sendo o planejamento metropolitano matéria da segurança e do desenvolvimento nacional (MONTE-MÓR, 2007, p. 87). O aumento na produção industrial foi, no entanto, "desacompanhado de políticas públicas adequadas, em termos não só de saneamento básico e habitação, mas também de redistribuição de renda" (BRANDÃO, 2012, p. 24), o que sugere uma profunda clivagem entre as políticas públicas de elaboração e execução dos planos. A configuração da paisagem de Canoas esteve ligada, portanto, a uma fase na qual os nexos econômicos impuseram-se como principal vetor para configuração do território das cidades, caracterizando o que foi chamado de "urbanização territorialmente seletiva" (SANTOS, 2004, p. 41) no Brasil.

Combasenesse lastro, nossa escrita foi motivada por questionamentos elaborados por meio de uma intersecção entre a história urbana ${ }^{7}$ e história ambiental $^{8}$. Procuramos agregar leituras pontuais em história ambiental e proposições para o estudo de cidades metropolitanas. $\mathrm{O}$ texto está dividido da seguinte maneira: primeiramente, compartilhamos proposições teóricas sobre o problema da história ambiental em geral e, particularmente, urbana. Em seguida, apresentamos Canoas como unidade de investigação e estabelecemos uma agenda de pesquisas de temas emergentes em história ambiental para os estudiosos do fenômeno metropolitano sobre a Grande Porto Alegre; por fim, arrematamos com as considerações finais.

\section{Algumas proposições sobre a história ambiental urbana}

A história ambiental é uma subdisciplina que vem enfrentando altos teores de autonomização dentro do conjunto do conhecimento histórico. Institucionalmente, ela é fruto do mundo universitário estadunidense, da era imediatamente posterior às grandes mobilizações por direitos civis neste

7 Sobre História Urbana, ver LEPETIT (2001).

8 Surgida nos anos 1970, a história ambiental nasce da impossibilidade de se negligenciar a pressão sobre os recursos ecológicos na duração histórica. $\mathrm{O}$ fundamento da história ambiental é a inserção do meio ambiente na história humana (WORSTER, 1991). 
mesmo país, tendo sido fortemente tributária das discussões envolvendo o lançamento do livro Silent Spring, da bióloga marinha Rachel Carson (1962). Socialmente, a história ambiental tem suas raízes numa manifesta sensibilidade - existente e identificada no Ocidente e nas Américas, desde o século XVIII - diante do avanço da economia humana em direção aos recursos da Terra (PÁDUA, 2004). De toda a forma, o pós-1945 aparece como o turning point da emergência planetária de uma noção partilhada de consciência ambiental (UEKÖTTER, 2005, p. 145).

Disciplinarmente, a história ambiental deseja observar a agência daquilo que denominamos "natureza" no curso da história. Por detrás deste aparente lugar pacífico, esta suposição encerra, todavia, graves questões; elas se reportam, entre outras coisas, a imaginar o lugar do "humano" na natureza e incidem sobre o próprio significado de natureza e humanidade, enquanto conceitos culturais fundamentais (SIMON, 2017). No scholarship em geral, imperaram abordagens biocêntricas e antropocêntricas; ora privilegiava-se o poder da natureza na moldagem de contextos históricos, ora aumentava-se o poder das sociedades humanas frente ao mundo natural. A partir dos anos 1990 emergiu a ideia de uma natureza cultural, fruto do avanço do linguistic turn no conjunto das ciências humanas (CAREY, 2009); tal tendência se mantém dominante no conjunto da historiografia contemporânea (ISENBERG, 2014).

Por consequência, pensar a natureza como um fator de cultura é, evidentemente, colocar em xeque a objetividade dos fatos aos quais reportamos como natureza e, assim, inseri-los nas estruturas da linguagem. Logo, os sentidos de natureza se abrem para muito além das ciências naturais e demais "ciências duras", pois estas passaram a ser vistas como produtos linguísticos capazes de fundamentarem discursos eficazes de objetificação científica. Tal estado de coisas liga-se à emergência de temas em história das ciências, das tecnologias e do conhecimento que, sob a consideração do pensamento pós-colonial, dos gender studies e dos estudos culturais, promoveram o questionamento das fortalezas da objetividade científica em prol de narrativas construtivistas. A história ambiental - que advogava inicialmente o uso das ciências naturais e da terra como instrumento de identidade epistemológica e assertividade científica - precisou reconhecer os novos tempos; a natureza tornou-se objeto de pesquisa cultural-discursiva e sua relação com a materialidade encontra-se em vias de negociação no interior da comunidade dos historiadores ambientais (DUARTE, 2005). 
Há outro risco em se escrever história ambiental e ele diz respeito, sobretudo, à materialidade da natureza e aos excessos das paixões políticas no scholarship; pois a escrita de uma história ambiental da natureza material não deve ser feita única e exclusivamente por meio de uma narrativa da destruição e declensionism (CORONA, 2009). O reforço do mito da natureza intocada e, em última instância, virginal, coloca-se como uma ameaça ao poder de esclarecimento da subdisciplina (DIEGUES, 2004). Decerto, o relacionamento humano com o mundo natural apresenta/apresentou aspectos apocalípticos em muitos momentos e lugares, mas ainda há muitas outras histórias ambientais a serem contadas, além daquelas destrutivas.

A história ambiental possui, portanto, a responsabilidade de contar histórias construtivas entre as sociedades humanas e a natureza (DUARTE, 2013). Nesse ínterim, a história ambiental das cidades oferece boas perspectivas, quando a cidade, ela própria, é encarada como uma espécie de nova natureza ou ecossistema, haja vista que o ecossistema urbano é formador de novas relações socioambientais e ecológicas (SHAPIRO, 2013). De todo modo, resta flagrante que as cidades latino-americanas demonstram conflitos variados e se incorporam em uma narrativa de danos ou que os seus desenvolvimentos possam ser imaginados na transição dos séculos $\mathrm{XX}$ e XXI através de um ecological bad.

Para o caso específico de Canoas e de seu desenvolvimento urbano, o artigo As cidades sem História, de Löic Vadelorge (2003/2) oferece pontos de reflexão, especialmente pela centralidade temporal do século XX na moldagem de sua fisionomia. Vadelorge afirmou que existe um hiato em relação aos estudos de cidades formadas na segunda metade do século XX, que nos remete "a problemas clássicos da História Contemporânea - dificuldades de abordar as épocas mais recentes -, mas, também, a problemas específicos das cidades novas" (2003/2, p. 21). O autor nomeia os historiadores de "verdadeiros abonados ausentes da História Contemporânea do Urbanismo" (2003/2, p. 23), ao criticar a carência de estudos historiográficos voltados às cidades novas. E não está sozinho: Annie Fourcaut, em seu texto História Urbana da França Contemporânea (2003/2), nomeia esse campo de investigação como um "continente ainda não explorado" (2003, p. 185) e ressalta o papel predominante exercido por pesquisas sobre as cidades capitais e sobre aspectos urbanos dissociados de questões ambientais.

Vale dizer que investigações locais se comprazem favoravelmente ao scholarship em história ambiental - sobretudo à história ambiental urbana (SCHOTT, 2004) -, pois a facilidade de acesso documental, centralizado 
em arquivos e instituições de controle e administração de bens ambientais citadinos, favorece a pesquisa nestes territórios. Obviamente, os problemas percebidos como locais podem ter ramificações suprarregionais e até transnacionais. Mas a ordem e a unidade de investigação dependem quase sempre do problema de investigação proposto (MCNEIL; MAULDIN, 2012). Sob a égide destes pressupostos, avançaremos na proposição de uma agenda de pesquisas em história ambiental para a RMPA a partir dos indícios fornecidos pelo caso de Canoas/RS.

\section{A cidade de Canoas, séculos XIX e XX: natureza e (variados) projetos urbanos}

A imagem ambiental de Canoas propagada a partir da última metade do século XIX é a de um espaço fugerem urbem, notoriamente por viajantes que percorriam a região. Conforme Torrão Filho:

De que fala, afinal, o viajante? De si mesmo ou do outro? A viagem fala da cidade, mas não apenas da cidade que vê e que descreve, a viagem teoriza a cidade, pensa, reflete; ela espelha devolvendo imagens invertidas, distorcidas, que falam mais da cidade do que supostas "fotografias" que nos devolvessem uma imagem estática, hierática. Ela reflete a cidade de forma dinâmica, viva, com movimento, sobretudo naquilo que mascara, esconde, tergiversa; a cidade está ali, ainda que nem sempre no mapa que nos é oferecido. (TORRÃO FILHO, 2011, p. 135)

Situada ao lado de Porto Alegre, Canoas tornou-se desde os anos 1870, facilmente acessível por membros das elites dos núcleos urbanos da capital e de São Leopoldo por meio de uma ferrovia (1874), convertendose em um espaço de lazer e de vilegiatura em meio ao verde e às águas. $\mathrm{O}$ território do município, no entanto, nunca se caracterizou por ser 
densamente florestado9. E a isso convinha a paisagem campestre-arbórea que transformou Canoas no recanto verde das maiores cidades em derredor. A localidade pertencia ao que os colonizadores luso-açorianos denominaram por Campos de Viamão, espaço preponderantemente gramíneo, pontilhados pelos chamados capões, que até hoje marcam a toponímia da cidade e são definidos como "ilhas florestais abruptamente separadas por uma matriz de campos" (COELHO et al., 2018, p. 245).

Assim, no testemunho de um viajante que visitou Porto Alegre em 1891, encontramos a observação que segue, relacionada aos então povoados de Canoas, Esteio e Sapucaia: "[...] logo se alcança a campanha, que, em parte, se compõe de terra arável e outra parte, a seguir, coberta com alterosas figueiras, de cujos galhos, pendem longas barbas-de-velho amareladas" (SCHANZ apud NOAL FILHO e FRANCO, 2004, p. 18). Saint-Hilaire, ainda na década de 1820 , ao se dirigir ao "Caminho Novo" do que veio a ser a colônia alemã de São Leopoldo, fundada em 1824, afirmava seu encanto pela paisagem europeizada e aberta de Canoas, ao visitar o Conde da Figueira, numa casa de campo que muito lhe agradou (SAINT-HILAIRE, 2002).

A presença de capões é um elemento expressivo na formação do município, substanciada pela historiografia local, que registra a própria cidade, durante um período, ter sido chamada de "Capão das Canoas". Um dos parques urbanos oficializado na década de 1980 - o Parque Municipal Getúlio Vargas -, é popularmente conhecido como Capão do Corvo ${ }^{10}$. Segundo Marchiori (2004), o termo capão (popularmente "capão de mato") tem origem na palavra oriunda do tronco tupi-guarani caa-apoam, que significa algo como "mata circular", caracterizando ilhas de vegetação dispersas em áreas campestres. Além disso, consta que os atuais Bairros Brigadeira e Industrial, que integravam a Fazenda Brigadeira ${ }^{11}$, foram outrora denominados "Campos de Baixo" e "Campos de Cima". Existiam, ainda, o Capão das Laranjeiras (Bairro Brigadeira), o Capão da Cruz, o Capão do Meio, o Capão Pequeno e o Capão das Capivaras (Bairro Industrial).

9 Pinheiro (2000) informa: 5,60\% é florestada. A vegetação é constituída por eucaliptos (Eucalyptus spp.) e pinheiro-americano (Pinus Elliottii). A ocupação urbana representa 46,62 da área municipal.

10 Nas áreas mais afastadas do lago do Capão do Corvo, a vegetação é de maior porte, sendo encontradas árvores nativas como açoita-cavalo, chal-chal, aroeira-vermelha (Schinus terebinthifolia Raddi) e capororoca (Myrsine guianensis (Aubl.) Kuntze) (FACHINELLO, 2012). Cabe ressaltar que a memória construída sobre a característica bucólica de Canoas tem sustentado aspectos identitários, objetivada em lugares como o parque citado.

11 Arquivo Público do Estado do Rio Grande do Sul. Saturnino Mathias Velho e Júlia de Souza Velho Processos de Inventário no 619 e no 2513 de 1924 e 1929, respectivamente, Porto Alegre -RS. 
Demais locais foram registrados na cartografia, que se valeu de diferentes nomenclaturas com inspiração em elementos da natureza local. Uma Planta datada de 1914, por exemplo, nomeia territórios do povoado, tais como: 5 Colônias, Mato Grande, Banhado Grande, Fazenda Mathias Velho, Fazenda Brigadeira, Fazenda Guajuviras, Campos Família Rosa e Capão Sujo. Questão instigante é aquela que remete às tipologias das árvores que compunham os capões descritos. A árvore símbolo de Canoas é a timbaúva, que integra a paisagem da cidade ao lado de outras espécies, como a guajuvira e a figueira. Segundo Fachinello, são algumas das espécies nativas da região:

[...] o açoita-cavalo (Luehea divaricata Mart. \& Zucc.), a aroeirabraba (Lithraea brasiliensis March.) e a chal-chal (Allophyllus edulis (A. St.-Hil., Cambess. \& A. Juss.) Radlk).), o branquilho (Sebastiania serrata (Baill.) Smith \& Downs), o catiguá (Trichilia clausseniia. C. DC.) e a canela-fedida (Nectandra megapotamica Mez) (FACHINELLO, 2012, p. 25).

Além dos capões, em meio aos campos, podemos destacar os arroios, os rios e os riachos. Mulhall, irlandês de Dublin e fundador do Buenos Ayres Standard $^{12}$, ao passar pelo território do futuro município canoense em 1874, encantou-se com os arvoredos nas margens dos rios dos Sinos e Jacuí, ao avistar o morro de Sapucaia (MULHALL, 1974). Não muito tempo depois, o viajante italiano Buccelli descreveu o Rio Gravataí, que banha Canoas, acompanhado de uma fotografia, em publicação que dedicou ao Rio Grande do Sul. O estrangeiro registrou em seu livro, Um viaggio a Rio Grande del Sud, publicado em Milão em 1906, que o rio "Gravataí surge sobre uma colina amena, dominando um território belíssimo, rico de todos os gêneros de vegetação e de terrenos férteis" (1906, s/p). 
Figura 1 - Margens do Rio Gravataí no final do século XIX.

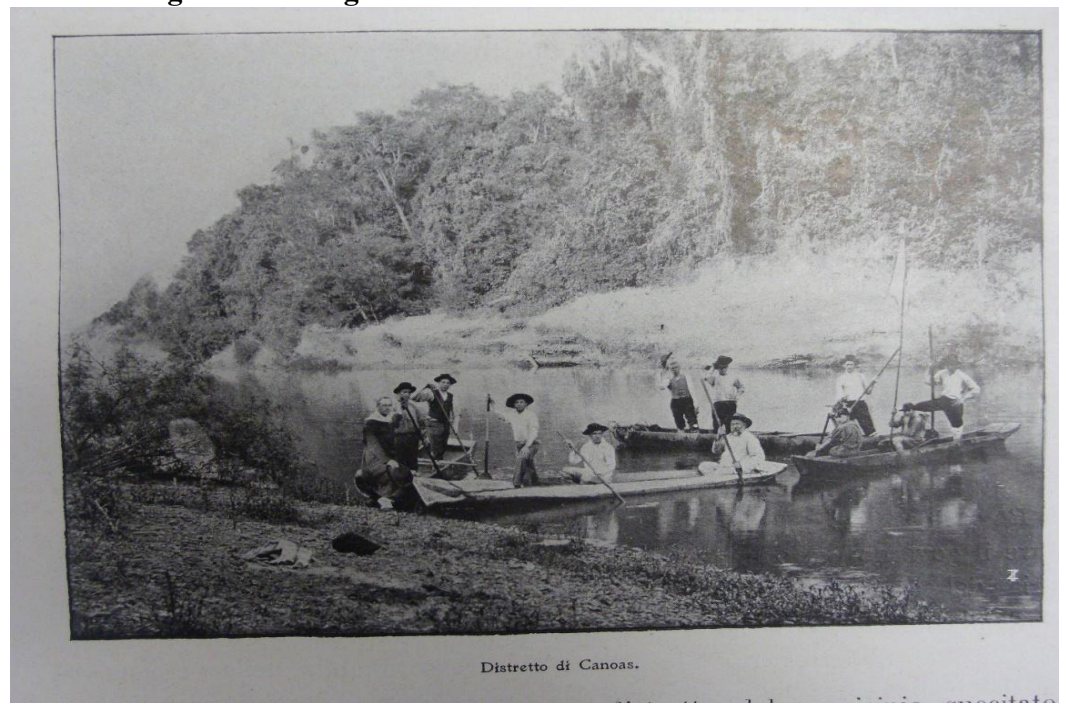

Fonte: Buccelli (1906).

Outro famoso ponto de sociabilidade era o chamado Arroio Araçá, hoje canalizado e coberto em quase toda a sua extensão. Até meados da década de 1930 era um elemento-chave da localidade, caracterizada por adjetivos como bucólica e aprazível. Os pequenos açudes compunham a paisagem natural da região. Sua existência, no entanto, não estava restrita à área central da cidade.

$\mathrm{O}$ engenheiro urbanista Ruy de Leiria ${ }^{13}$, em um arrojado projeto urbanístico (1948), declarou que em torno de 1/3 (um terço) ou 1/4 (um quarto) do território de uma cidade deveria ser dominado por áreas verdes e que Canoas detinha potencial para ter uma grande reserva ambiental. Para aplicar tal teoria, o profissional elegeu a área denominada Vila Fernandes, alegando que o local tinha condições soberbas para ser transformado em parque. Isso porque o local estava ainda isento de loteamento e destacavamse lá capões, pomares e uma lavoura. Deduz-se que esses elementos compunham a vegetação natural que facilmente poderia ser aproveitada como motivos paisagísticos pelo urbanista. Ao centro dessa área verde, haveria a grande atração: um açude, a ser aparelhado com motivos ornamentais. Para 
a preparação do local, o urbanista previa a desapropriação de 28 hectares de terra, sendo 21 destinados a um parque.

Para além desses espaços de recreação, outro universo se projetava quanto ao espaço ambiental metropolitano onde, no geral, muitos dos bairros tiveram sua origem em arrozais, como é o caso de Niterói, zona sul de Canoas. A chamada Villa Nictheroy encontra no seu próprio nome a estreita relação que possui com o Rio Gravataí, uma vez estando registrado que Nictheroy significa "lugar de águas ocultas". Esse território nos fornece um exemplo para refletir sobre a relação entre a história ambiental e a história social de determinadas cidades, a partir das enchentes. Segundo Alexandre Fortes, tal vivência implica elementos naturais e sociais, pois "[...] não expressa uma noção de comunidade pré-estabelecida, mas sim, o resultado de uma reelaboração da experiência vivida e dos diferentes discursos que, ao interpretá-la, procuram incidir sobre a própria definição do que se constituiu a comunidade" (2001, p. 99).

A localização de Niterói foi considerada prejudicial pelo já citado engenheiro urbanista Ruy de Viveiros Leiria. Segundo o profissional, "bem diverso de seu irmão, o Nilo, que deixava, ao retirar-se para leito, só fertilidade e riqueza [...] o Gravataí deixa ficar atrás de si apenas esterilidade e miséria" ${ }^{14}$. Quanto à infraestrutura, Leiria identificou o bairro como insalubre, citando mais uma vez o espaço inadequado onde os moradores foram estabelecidos que, de acordo com o engenheiro, foram em terras que há poucos anos eram campos de prósperas empresas orizícolas. 
Figura 2 - Vista da Villa Nictheroy (1928).

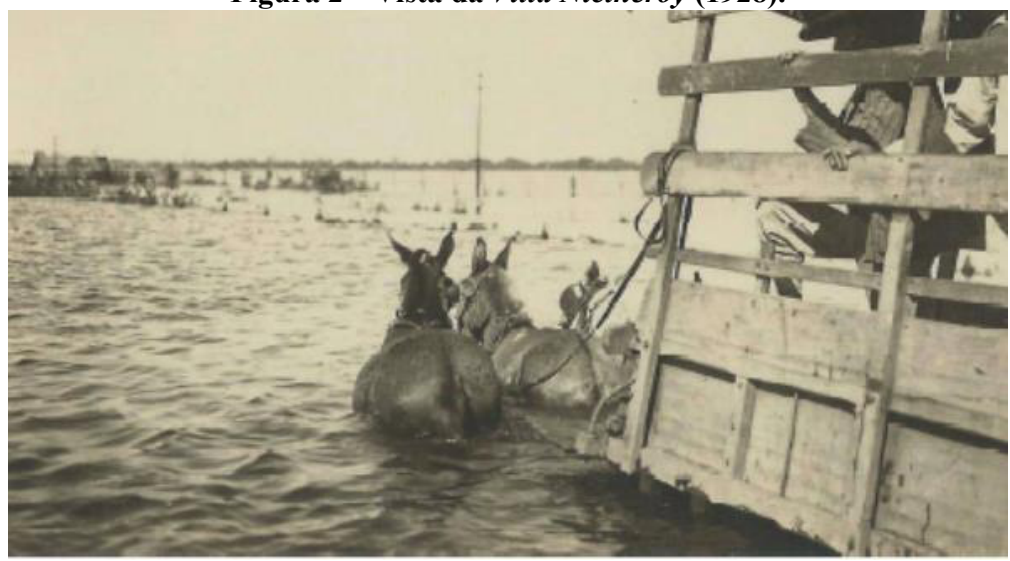

Fonte: acervo do Arquivo Municipal Sezefredo Azambuja Vieira (Canoas, RS).

Em idos de 1941, por exemplo, a situação foi de completo flagelo público. Centenas de pessoas refugiaram-se no Terceiro Regimento de Aviação de Canoas. Tais informações são respaldadas por testemunhas que presenciaram o ocorrido, como Jacó Wobeto, que relaciona a grande cheia do início da década de 1940 a calamidades anteriores. Ele narra que:

[em 1936] andava-se só de barco. Perdemos toda a plantação. Só não perdemos as galinhas porque elas ficaram em cima das bananeiras que flutuavam e também ficavam em cima da casa. Conseguimos salvar alguns porcos. Mas a enchente de 1941 nos deixou apavorados. Chegou no telhado da casa. Depois dessa enchente meu pai não quis mais saber de plantar (WOBETO, informação verbal, 1994).

As enchentes continuaram a ser um ponto-chave da história socioambiental de Canoas nas décadas seguintes, especialmente junto aos grandes loteamentos configurados no município em idos de 1950. O mais conhecido deles está localizado a noroeste da cidade: trata-se da Vila Mathias Velho. José Ferreira, nascido em São Francisco de Paula em 1942, conta que elegeu o loteamento como local de habitação, porque: 
[...] não tinha lugar mais barato. O falecido meu pai tinha parentes que moravam em Niterói, tinha na Tamoio, ele falava para eles e dizia: olha, barbada é só a Mathias! É lá! Eles vieram para cá, foram naquela rua, era mais barato do que aqui. Era na Rua Manaus. De lá até essa Rua tem umas quatro quadras. Era mais caro. Mais para o fundo era mais barato ainda. $\mathrm{O}$ pessoal ficava por aqui por causa da condução (FERREIRA, informação verbal 2000).

Em abril de 1951, a Sociedade Territorial São Carlos assumiu com a Prefeitura de Canoas o compromisso de urbanizar uma área de 786 hectares, referente à chamada "Vila São Carlos", posteriormente nominada "Vila Mathias Velho". Durante o mês de novembro a aludida Sociedade alegava "dificuldades de ordem material e comercial para a venda de todos os lotes", declarando estar "grande parte do terreno arrendado para a cultura de arroz e criação de gado" (SOLICITAÇÃO, 1951).

Já em 1954 há um processo através do qual a Sociedade Territorial São Carlos - que, naquele momento já era responsável pelos loteamentos das Vilas "Chácara Rasgado", "Julieta" e "Igara" - solicita ao Poder Público que reconsiderasse a interrupção dos ditos loteamentos, tendo em conta que a Sociedade trabalharia para executar os compromissos devidamente assumidos quando da autorização para criar as Vilas, ainda em 1951. Entre as obrigações, figuravam "executar, por conta da Sociedade, e sem qualquer ônus para a Prefeitura, todas as obras necessárias à abertura das ruas e avenidas projetadas na Planta, bem como as valetas de drenagem que irão assegurar um perfeito saneamento dos terrenos" na Vila Mathias Velho, além da construção "de um grande canal de escoamento de águas pluviais que, partindo de um ponto distante cerca de 500 metros da faixa de concreto, terminaria no Rio dos Sinos, coletando todas as águas dos terrenos em questão", no mesmo loteamento (MEMORANDO, 1954).

A paisagem natural de Canoas em idos da década de 1960 era transformada, portanto, em prol da execução de loteamentos que avançavam sobre antigas plantações de arroz e próximos às margens dos rios Gravataí e dos Sinos. Paralelamente, outro cenário se impunha: em 1961, a Lei n. 665 autorizou a redução de $30 \%$ nos lançamentos de impostos sobre indústrias; ela foi seguida, em 1962, pela Lei n. 739 que as isentava totalmente de tributação. Ao que tudo indica, tais incentivos fiscais aceleraram a 
construção de uma cidade industrial, fator determinante para a conversão da antiga cidade veraneio, já bastante deteriorada por conta de inúmeros loteamentos. Há de ser citado o papel dos territórios rurais de Canoas à época. Não faltavam sugestões para o melhor aproveitamento das terras e da sua inserção definitiva no projeto de Canoas como um reduto de indústrias. Pelo menos não por parte do jornal $O$ Momento, que escreveu e ilustrou um projeto de industrialização para Santa Rita, segundo distrito da cidade. Lê-se em matéria chamada "Tudo pela Industrialização de Canoas" que, a despeito de ter sido reconhecido como um impulsionador da economia local, devido a sua grande produção de hortifrutigranjeiros, o território de Santa Rita seria pensado como um abrigo de indústrias.

Indiscutivelmente, a salvação da cidade de Canoas está em sua industrialização. É a grande batalha que teremos de travar nos próximos anos. A área circundada pela tinta vermelha no clichê, à direita, vemos a imensidade de terreno que poderia ser aproveitada na industrialização da cidade. Construída a ponte sobre o Rio dos Sinos, estará resolvido o problema da ligação ao segundo distrito com a Sede do Município. Isso facultará o maior desenvolvimento daquela região. E, nos parece, é o lugar mais apropriado para a construção do futuro parque industrial da cidade. Desde Morretes, até o Morro da Boa Vista, estendese uma área imensa que poderá ser aproveitada. É verdade que existem pequenas culturas nestas terras, mas, são quase todas culturas anti-econômicas, que muito bem poderão ser substituídas por fábricas ou oficinas"15 (grifo nosso).

Destaca-se, neste sentido, aquela indústria que foi símbolo de Canoas como uma cidade industrial: a Refinaria Alberto Pasqualini inaugurada no município em 1968. Na época, surgem várias parcerias entre as escalas municipal, estadual e nacional, voltadas às políticas públicas de habitação, como o Banco Nacional de Habitação (BNH). O recém-mencionado ano de 1968 marca, também, o início do planejamento da Região Metropolitana de Porto Alegre (RMPA), que veio a ser instituída oficialmente em 1973. 
A década de 1980, enfim, ilustra um caso exemplar no plano da história ambiental da RMPA: a ocupação do Bairro Guajuviras, zona leste do município, considerada a maior da história do Rio Grande do Sul. Mais uma vez, indícios do tempo presente são válidos, quando nos reportamos ao Bairro Guajuviras, que presta homenagem a uma árvore típica da região e que detém, ainda, em seu território uma Unidade de Conservação (UC). Com origem em antigas fazendas (Renner e Guajuviras) desapropriadas pelo governo estadual, nos anos finais do governo João Figueiredo, as terras começaram a receber a construção de extenso conjunto habitacional com as chamadas "casas populares", planejado junto ao que se entende como conjunto de gestores que concebiam cidades com ações e estratégias impositivas, a saber, o Grupo Executivo da Região Metropolitana de Porto Alegre-GERM, o Banco Nacional da Habitação-BNH e a Companhia de Habitação do Estado do Rio Grande do Sul-COHAB. Desse consórcio surgiu o Conjunto Habitacional Ildo Meneghetti, batizado localmente como Guajuviras, com 5.974 unidades habitacionais.

Construídas as habitações, estas não foram entregues aos seus compradores, pois a empresa administradora das obras enfrentava sérios problemas financeiros advindos da política econômica vigente, incluindose a extinção do BNH em 1986. A partir de 1979 deu-se a sua construção e, no ano de 1987, narrativas sobre o conjunto habitacional dão conta de que, “[...] as casas já estavam apodrecendo, estavam caindo muitas casinhas ou casebres, se assim pode-se chamar. Então o povo naquela manhã [04/1987] invadiu. Foram trinta mil pessoas que entraram" (HARTMANN, Engilberto apud PENNA et. al., 1998, p. 14). A falta de praças, parques, áreas para lazer, terrenos onde se acumulavam o lixo e animais mortos e o crescente índice de ocorrência de crimes fomentou movimentos dos moradores, procurando curar as feridas de suas lutas para regularização das moradias e reconstrução identitária até os dias atuais.

Um dos principais desdobramentos do vertiginoso processo de urbanização de Canoas foi, portanto, a degradação ambiental de localidades outrora reconhecidas por seus elementos naturais e que, no cenário do tempo presente, passaram a serem caracterizados por altos índices de poluição, loteamentos sem infraestrutura urbanística e avanço de construções em espaços florestados. A título de ilustração, trazemos duas imagens de Canoas nas quais pode visualizar-se o mesmo espaço no intervalo de cerca de 70 anos (década de 1930 e década de 2000). 
Figura 3 - Canoas (Década de 1930).

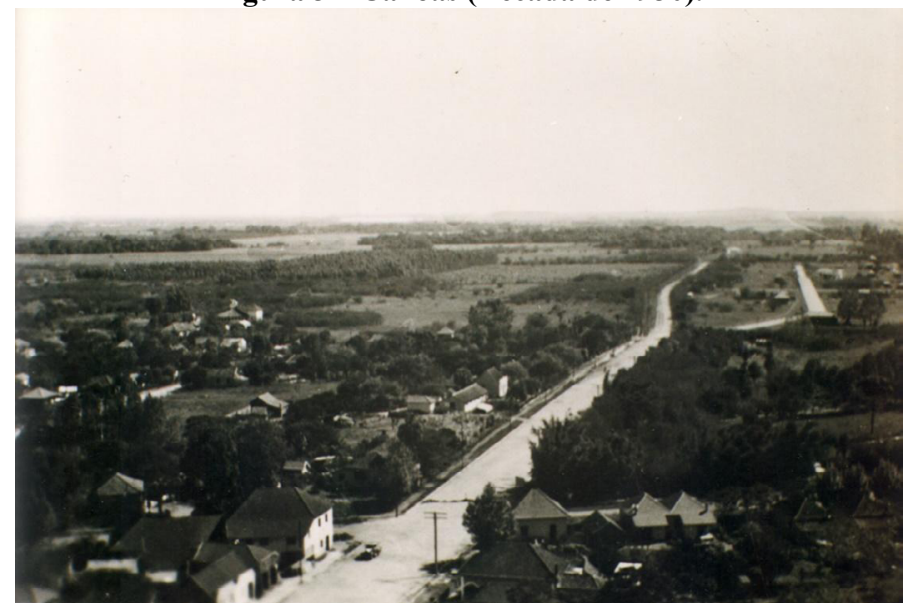

Fonte: Museu e Arquivo Histórico La Salle

Figura 4 - Canoas (Década de 2000).

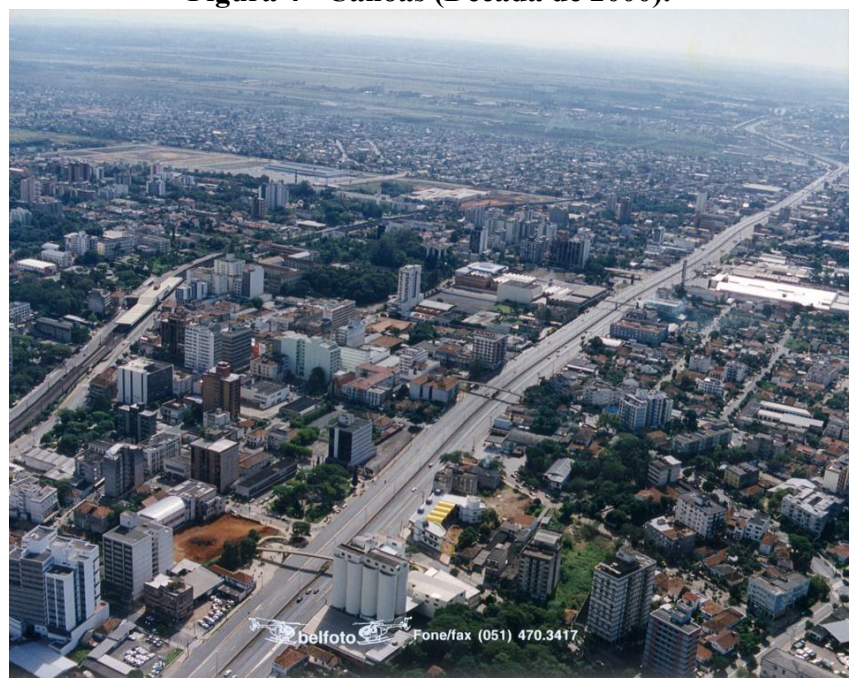

Fonte: Museu e Arquivo Histórico La Salle 
A preocupação com as questões ambientais na região metropolitana quando de seu planejamento estava restrita a pequenos grupos que militavam em organizações não governamentais como a Associação Gaúcha de Proteção ao Ambiente Natural/AGAPA ${ }^{16}$, criada em Porto Alegre em 22 de abril de 1971, inspirada na União Protetora da Natureza-UPN (fundada por Henrique Luís Roessler, São Leopoldo/RS, 1955) e em movimentos internacionais. ${ }^{17}$ Sequencialmente, quesitos tais como treinamento de pessoal, controle de poluição ao nível metropolitano, montagem de um esquema de coleta de lixo, tratamento de esgoto, gerenciamento de reservas ambientais e pesquisa de bacias hidrográficas foram lançados no Plano de Desenvolvimento Metropolitano de Porto Alegre (PDM).

Em Canoas, foi criada na década de 1980 a Associação Canoense de Proteção Ambiental/ASCAPAN, declarada de utilidade pública para fins de preservação do ambiente natural pelo Decreto 478/1984 ${ }^{18}$. A entidade ao longo do tempo tem atuado na prevenção e no combate a acidentes ambientais na cidade, bem como na proposição de planejamento integrado de desenvolvimento sustentável. A cada ano, a ASCAPAN divulga o que chama de Lista Suja, com ameaças ambientais em Canoas e nas cidades próximas: depósitos de agrotóxicos, dutos que conduzem nafta petroquímico para o Polo Petroquímico de Triunfo, transporte de produtos perigosos, vazamento de amônia, entre outros (ARRUDA, 2009).

Nos dias de hoje, Canoas figura entre os Municípios mais industrializados do Rio Grande do Sul e conta com um dos maiores Produtos Internos Brutos do Estado, expandindo a apropriação de espaços com resquícios dos antigos capões. $\mathrm{O}$ desenvolvimento urbano da cidade foi legitimador de uma expansão urbana que não é específica da localidade, mas componente de um projeto nacional de industrialização cujas consequências ambientais ainda não foram totalmente mensuradas. Desta forma, encaminhamos uma proposta de agenda de tópicos de estudo e pesquisa em história ambiental.

\section{Por uma agenda de pesquisas em história ambiental da RMPA}

Haja vista a introdução ao processo de mudança paisagística 
enfrentado por Canoas, que exemplifica o próprio desenvolvimento histórico e urbano de municípios vizinhos durante o século XX, elencamos um programa de pesquisas em história ambiental. Tal lista não se pretende exaustiva:

1) Uma história do uso dos espaços gramíneos e capões que perfaziam a identidade fitogeográfica do local. Uma história dos recursos aliada à pecuária e agricultura, a existência ou não de faxinais (sistemas integrados campo-floresta comuns no Sul do Brasil em áreas de ecótono), o uso propriamente agrícola (orizicultura e hortifrutigranjeiros) do território, e a transformação da paisagem em espaço de vilegiatura são elementos, até o momento, desconhecidos da historiografia. No caso específico da vilegiatura, uma história da cultura do verde, do escapismo, do bucolismo pode se encontrar bem com uma história dos usuários destes espaços, muitos deles provenientes da Europa e donos de repertórios culturais frente à natureza. Paisagismo e fruticultura podem ser temas de pesquisa neste campo, pois há testemunhos históricos que a suportam sob a pena de viajantes europeus.

2) História das águas, de sua gestão, distribuição e uso. Canoas e outras cidades da RMPA localizam-se na foz do estuário do Jacuí e Sinos e, além disso, as características orográficas e edáficas deste espaço as predispõem à formação de pântanos, charnecas e brejos. Enchentes, chuvas e banhados foram componentes que atravessam a constituição destas cidades. Uma história das águas e de seu controle caberia numa história da orizicultura regional, pois a cultura do arroz demanda quantidades volumosas de água. A construção de diques de contenção de enchentes e obras hidráulicas também deve ser pensada sob o prisma do impacto das mesmas sobre a comunidade; ademais, uma história de transferência de tecnologias hidráulicas pode ser desenvolvida, tendo em vista o envolvimento de técnicos estrangeiros no planejamento do controle das águas fluviais e pluviais. Uma história da salubridade da água e de sua distribuição, além de uma cronologia do saneamento básico promete interessantes aportes, considerando a ocupação desenfreada de vastas áreas e arrabaldes das cidades da RMPA. O uso da água para fins industriais é, igualmente, um importante capítulo a ser escrito e atinge a região de modo transversal. Lembramos, igualmente, no 
que concerne à água, pensar a pesca e seu impacto na economia local em perspectiva histórica.

3) História do ambientalismo e história dos animais. A história da cultura do meio ambiente e da emergência da consciência ambiental na sociedade; a história de áreas reservadas e de unidades de conservação existentes no território do município (Área de Proteção Ambiental Estadual Delta do Jacuí e Parque Estadual Delta do Jacuí), além do urbanismo de parques e praças; outro aspecto mais recente, porém associado ao ambientalismo como cultura de massa, é o surgimento da noção do bem-estar animal e o impacto do mundo PET na estrutura urbana - temas explorados inclusive por atores políticos locais e referenciados, frequentemente, na economia de reciclagem de lixo e dejetos praticada por atores em risco social e por vezes organizados em cooperativas.

4) História dos resíduos sólidos e efluentes. Urbanização e industrialização historicamente geraram novos desafios na condução e gestão de resíduos sólidos e efluentes. Esta questão é dramática, quando percebemos o potencial de contaminação da água e do solo, pois Canoas e RMPA são áreas de grande profusão de banhados e localizam-se na foz de importantes sistemas fluviais. O destino do lixo, aterros e legislação são temas importantes ao historiador ambiental e de grande relevância social.

5) Poluição do ar e sonora. Intimamente ligadas, a poluição sonora e do ar são elementos estruturantes da vida das populações de Canoas e da RMPA. Cortadas por rodovias e ferrovias de trânsito intenso, além da proximidade com terminais aeroportuários civis e militares, a região sofre com os impactos dos principais modais de transporte acoplados ao sistema econômico e de emprego. Uma análise em termos de impacto de qualidade de vida ainda espera por seu historiador.

6) Uma história do imaginário da natureza. Moradores de Canoas e da RMPA vem sofrendo, nas últimas décadas, a depauperação da qualidade ambiental de seus entornos. Crime, poluição, violência urbana, especulação imobiliária, ausência de áreas verdes e de lazer, 
etc., são problemas enfrentados por vastas camadas da população. Não raro percebe-se a vontade em se retornar a uma "era perdida" onde a natureza penetrava com vigor na vida e nos afazeres de crianças, jovens, adultos e idosos. Esta natureza seria sobretudo - e erroneamente no caso de grande parte da RMPA - de ordem florestal, pois a região foi e é formada por áreas grassland alicerçadas por ilhas arbóreas (capões). Entender o porquê da identificação da natureza com a floresta e a exclusão da área de campo do mundo da natureza é um bom exercício de uma história ambiental do imaginário da natureza. Os campos e savanas são paisagens mais antigas do que as florestas no Brasil. Cabe ao historiador ambiental entender esta associação e recolocá-la em discussão na sociedade, pois este é um problema que atinge, inclusive, as políticas de conservação do bioma gramíneo do Pampa.

\section{7) Uma história da memória e das identidades ambientais. Nesse} sentido, é relevante estudar as narrativas de moradores de diferentes gerações sobre as questões ambientais urbanas, por meio de pesquisas que utilizam a metodologia da História Oral. No caso de nossas pesquisas, parte dos moradores de Canoas ${ }^{19}$ narraram sobre uma cidade com uma paisagem bucólica; já outros lamentaram a substituição desta por ambientes poluídos e por espaços asfaltados, pela presença de periferias e ausência de áreas verdes. Aqui, para além do enunciado, é necessário considerar as condições em que a narrativa foi produzida, pois como coloca Alberti, essas "[...] devem ser, elas mesmas, objeto de análise" (2013, p. 160). Neste caso, a narrativa documenta como o morador quer ser visto e o que deseja falar para o entrevistador em um momento único - o da entrevista. É nesse espaço de tempo que expressa suas experiências de vida. Mesmo tendo esse caráter particular, a entrevista pode ser tomada no sentido de documentar como, em determinado momento, os moradores colocam suas representações sobre determinada realidade ambiental, tanto como elementos de suas próprias histórias de vida quanto do ambiente urbano em que habitam.

19 Projeto "Canoas - Para lembrar quem somos", desenvolvido em parceria com a Prefeitura Municipal de Canoas desde 1994. 


\section{Considerações finais}

Era o ano de 1978 quando João Palma da Silva, um conhecido memorialista de Canoas, escreveu que a História da cidade "[...] movida por seu desenvolvimento industrial e comercial, é recente demais para ser escrita e interpretada" (SILVA, 1978, p. 57). A frase carrega consigo a ideia de que o distanciamento temporal por parte do historiador traria soluções de interpretação. Em outras palavras, segundo o autor, escrever a história de Canoas no ano de 1978 era tarefa ingrata, estando o memorialista situado espacial e temporalmente em pleno "olho do furacão" do processo histórico que almejava investigar. Tal fato, de acordo com ele, o impediria de estabelecer uma escrita idônea sobre o passado da cidade de Canoas. A solução vislumbrada por João Palma da Silva, na época, foi a de divulgar uma extensa cronologia com a missão de destacar os fatos de maior relevância em sua análise do passado da cidade de Canoas, tendo em mente que essa alternativa era adversa ao caminho necessariamente interpretativo e parcial que a narrativa iria impor ao seu trabalho.

Hoje, quarenta anos após a referida afirmação, buscamos compor uma trama narrativa que não é medida pela distância temporal em relação aos fatos que se deseja averiguar, mas por uma parcialidade incorporada como um elemento próprio à posição ativa que o historiador ocupa no fazer historiográfico; nesse ínterim, objetivou-se evocar a perspectiva ambiental como uma das inúmeras possibilidades de escrita da história de cidades metropolitanas recentes.

A história ambiental, no caso específico das regiões metropolitanas, oferta-se como profícua pois seu programa de pesquisas é particularmente sensível aos objetos da natureza, que possuem íntima relação com a estruturação de paisagens e a vida dos grupos humanos; ela é por si só muito abrangente e toca aspectos relativos ao uso dos recursos naturais e se estende até às visões e ideias que as pessoas fazem dos mesmos; não menos importante é a discussão da emergência da política de uso de recursos alicerçada nas decisões governamentais tecnocratizadas e no ambientalismo. Com efeito, são inúmeros os temas sobre questões ambientais e demandam a familiaridade de outros alfabetos científicos e linguagens do saber. Nesta pesquisa, entendemos o estudo apresentado, para além de suas conclusões, notavelmente como um propiciador de uma agenda programática de investigações futuras. 
De todo o modo, a conversão da RMPA em seu estado presente demanda o debate sobre a qualidade de vida, direito à cidade e projetos de futuro. Uma história ambiental honesta precisa ouvir as vozes silenciadas no processo de gestão territorial e apresentar à sociedade, alternativas quanto a esse. Gerir territórios é uma atividade em ato contínuo e afeta diretamente a vida das pessoas. A paisagem é uma herança (AB'SÁBER, 2005) e por isso a história ambiental da RMPA é um tema de interesse contemporâneo.

\section{Referências}

AB'SÁBER, Aziz. Os domínios de natureza no Brasil: potencialidades paisagísticas. Cotia: Ateliê Editorial, 2005.

ACKER, Antoine. Volkswagen in the Amazon: The tragedy of global development in modern Brazil. Cambridge: Cambridge University Press, 2017.

ALBERTI, Verena. De "versão" a "narrativa" no Manual de história oral. História Oral, v. 15, n. 2, jul./dez. 2012, p. 159-166. Disponível em: http:// bibliotecadigital.fgv.br/dspace/bitstream/handle/10438/24593/263-816-1PB.pdf? sequence=1\&isAllowed=y. Acesso em 20 jul. 2019.

ARRUDA, Arlete Aparecida H. de. Análise dos processos decisórios em face dos riscos tecnológicos: a percepção de riscos, as consequências dos acidentes e os gestores públicos na cidade de Canoas-RS. Tese. Doutorado em Ciências Sociais. Programa de Pós-Graduação em Ciências Sociais, Universidade do Vale do Rio dos Sinos. São Leopoldo/RS, 2009.

BRANDÃO, Carlos. Território e Desenvolvimento. As múltiplas escalas entre o local e o global. Campinas, SP: UNICAMP, 2012.

BUCCELLI, Vitorio. Un viaggio a Rio Grande del Sud. Porto Alegre: [s. n.] (Milano: L. F. Palestrina), 1906.

CALABI, Donatella. História do urbanismo europeu: questões, instrumentos, casos exemplares. São Paulo: Perspectiva, 2012.

CAREY, Mark. Latin american environmental history: current trends, interdiciplinary insights, and future directions. Environmental History, 
2009/v.14, p. 221-252, 2009.

CARRION, Otilia K. Mercado imobiliário e padrão periférico de moradia: Porto Alegre e sua Região Metropolitana. Ensaios FEE, Porto Alegre, v. 10, n. 2, p. 225-250, 1989.

CARSON, Rachel. Silent spring: 25th anniversary. Boston: Houghton Mifflin Co, 1987.

COELHO, Marcel S.; SIQUEIRA NEVES, Frederico de; PERILLO, Lucas N.; MORELLATO, Leonor P. C.; FERNANDES, G. W. Forest archipelagos: a natural model of metacommunity under the threat of fire. Flora. v. 238, 2018, p. 244-249.

CORONA, Gabriella. On Nature and Power: Interview with Joachim Radkau. In Global Environment 2009/3, p. 262-277.

DÉAK, Csaba. O processo de urbanização no Brasil: falas e façanhas. IN: DÉAK, Csaba; SCHIFFER, Sueli Ramos (Orgs.). O processo de urbanização no Brasil. São Paulo: Ed. da USP, 1999.

DECRETO 478/1984. Disponível em: https://leismunicipais.com.br/a1/rs/ c/canoas/decreto/1984/48/478/decreto-n-478-1984-declara-de-utilidadepublica-para-fins-de-preservacao-do-ambiente-natural-a-ascapan-associacaocanoense-de-protecao-ao-ambiente-natural. Acesso em 20 ago. 2018.

DIÁRIO DE NOTÍCIAS (Jornal). Porto Alegre, 24.12.1944.

DIEGUES, Antonio Carlos Sant'ana. O mito moderno da natureza intocada. São Paulo: Hucitec, 2004.

DOSSE, François. História do tempo presente e Historiografia. Tempo e Argumento. Florianópolis, v. 4, n. 1, p. 5-22, jan./jun. 2012. Disponível em: http://www.revistas.udesc.br/index.php/tempo/article/view/217518030401 2012005. Acesso em 10 julho 2018.

DUARTE, Regina Horta. História \& natureza. Belo Horizonte (MG): Autêntica (Historia \& Reflexões), 2005.

DUARTE, Regina Horta. Scheherazade tropical: Narrativas e diálogos da história ambiental no Brasil. In História, v. 32, n. 2, 2013, p. 3-20.

FACHINELLO, Alexandra. O patrimônio ambiental em Canoas, Rio Grande do Sul: avaliação da conservação e recomendações de uso de áreas naturais 
remanescentes. Disponível em: https://biblioteca.unilasalle.edu.br/docs online/tcc/mestrado/memoria_social_e_bens_culturais/2012/afachinello. pdf. Dissertação de Mestrado. Programa de Pós-Graduação em Memória Social e Bens Culturais do Centro Universitário La Salle-Unilasalle, 2012.

FRANCO, Sérgio da Costa; NOAL FILHO, Valter Antonio. Os viajantes olham Porto Alegre: 1890-1941. Santa Maria: Anaterra, 2004.

FELDMAN, Sarah. Planejamento e Zoneamento. São Paulo, 1947-1972. São Paulo: EDUSP/FAPESP, 2005.

FERNANDES, Ana. Urbanismo como política (1930-1945): formulações e experiências. IN: REZENDE, Vera (Org.). Urbanismo na Era Vargas: a transformação das cidades brasileiras. Niterói: UFF/Intertexto, 2012, p. 45-70.

FERREIRA, José Genésio Martins. José Genésio Martins Ferreira: depoimento [2000]. Entrevistador: Miguel Gaieski. Canoas/RS: 2000. Entrevista concedida ao Projeto Canoas: para lembrar quem somos Mathias Velho. Acervo do Museu Histórico La Salle-MAHLS.

FORTES, Alexandre. Nós do quarto distrito: a classe trabalhadora portoalegrense e a Era Vargas. Tese de Doutorado, Programa de Pós-Graduação em História, UNICAMP, 2001.

FOURCAUT, Annie. L'Histoire Urbaine de la France Contemporaine: état des lieux. Histoire Urbaine, n. 8, p. 173, 2003/2.

GERHARDT, Marcos. Um olhar sobre a história dos movimentos ecologistas no Rio Grande do Sul. Anais do XXVI Simpósio Nacional de História ANPUH, São Paulo, julho 2011. Disponível em: http://www.snh2011.anpuh. org/resources/anais/14/1308137853_ARQUIVO_ecologistas-rs-final.pdf. Acesso em 21 ago. 2018.

ISENBERG, Andrew C. A New Environmental History: The emergence of a new field. In: ISENBERG, Andrew C. (Org.): The Oxford handbook of environmental history. Oxford, New York: Oxford University Press, p. 1-22.

KARPE, Hans; TRINIDADE, Sergio C. (Eds.). Climate and development: climate change, variability and the resulting social, economic and technological implications. Germany: United Nations, 1990.

LEIRIA, Ruy de Viveiros. Pré-Plano para a cidade de Canoas. Revista de Engenharia do Rio Grande do Sul, Porto Alegre, n. 14, ano IV, p. 53-73, set. 1948. Acervo Biblioteca IPH, UFRGS. 
LINDMAN, Carl A. M. A vegetação no Rio Grande do Sul. São Paulo: EDUSP, 1974[1906].

LUTZENBERGER, José A. Por uma ética ecológica. Correio do Povo, 29/08/1971, p. 22.

MEMORANDO de solicitação à Prefeitura Municipal de Canoas para construir em diversas vilas da cidade de Canoas. Requerente: Sociedade Territorial São Carlos, 1954. Acervo Arquivo Municipal Sezefredo Azambuja Vieira (Canoas, RS).

PARECER da Câmara Municipal de Canoas sobre o pedido da Sociedade Territorial São Carlos de isenção de impostos, 1952. Acervo UPHAMCanoas.

MARCHIORI, J. N. C. Dendrologia das Angiospermas: Leguminosas. Santa Maria: Ed. da UFSM, 2007.

MARTINS, Clítia. Região Metropolitana de Porto Alegre: dinâmica legal e institucional. Indicadores Econômicos FEE [online] 20:2. jul. 2008. Disponível em: http://revistas.fee.tche.br/index.php/indicadores/article/ view/695/940. Acesso em: jun. 2017.

MCNEIL, J. R.; MAULDIN, E. S. Global Environmental History: an Introduction. In John Robert McNeill, Erin Stewart Mauldin (Eds.): $A$ companion to global environmental history. Malden, Mass.: Wiley-Blackwell (Wiley-Blackwell companions to history), 2012, p. xvi-xxiv.

MONTE-MÓR, Rodrigo. Planejamento Urbano no Brasil: Emergência e Consolidação. Etc.: espaço, tempo e crítica. n. ${ }^{\circ}$ 1(4), vol. 1, 15 de junho de 2007.

MULHALL, Michael G. O Rio Grande do Sul e suas colônias alemãs. Porto Alegre: Bels, 1974.

O MOMENTO (Jornal), Canoas, 05.03.1956.

PÁDUA, José Augusto. Um sopro de destruição. Pensamento político e crítica ambiental no Brasil escravista, 1786-1888. Rio de Janeiro: Jorge Zahar Editor, 2004.

PENNA, Rejane (Coord.). Guajuviras: História de uma luta. Canoas: SMEC-DPESA, 1998.

PINHEIRO, Eduardo da Silva. Integração de sistemas de informações 
geográficas e legislação ambiental: um subsídio para a gestão das formações vegetais do Município de Canoas-RS. Monografia (Bacharelado em Geografia). Instituto de Geociências da UFRGS, Porto Alegre, 2000.

REIS, Karina dos Reis. A Cidade e o Elemento Natural: o Parque Marinha Do Brasil e as Políticas Públicas do verde em Porto Alegre (1960-1970). Dissertação de Mestrado. Programa de Pós-Graduação em História. PUCRS, 2011.

SAINT-HILAIRE, Auguste de. Viagem ao Rio Grande do Sul, 1820-1821. Brasília: Senado Federal, 2002.

SANTOS, Milton. A urbanização brasileira. 5. ed. São Paulo: Ed. da USP, 2013.

SCHOTT, Dieter. Urban environmental history: What lessons are there to be learnt. In Boreal environment research 9 (6), 2004, p. 519-528.

SEDREZ, Lise. Urban Nature in Latin America: Diverse Cities and Shared Narratives. In: RCC Perspectives 7, 2013, p. 59-66.

SHAPIRO, Aaron. Nature Next Door: Cities and Trees in the American Northeast. In Environmental History, v.18 n.4, 2013, p. 811-812.

SILVA, Delci Pacheco da. Delci Pacheco da Silva: depoimento [2000]. Entrevistador: Miguel Gaieski. Canoas/RS: 2000. Entrevista concedida ao Projeto Canoas: para lembrar quem somos - Mathias Velho. Acervo do Museu Histórico La Salle-MAHLS.

SILVA, João Palma da. Pequena História de Canoas - cronologia. Canoas: La Salle, 1978.

SIMON, Zoltán Boldizsár. Why the Anthropocene has no history: Facing the unprecedented. In The Anthropocene Review, v. 4, n. 3, 2017, p. 239-245.

SOARES, Paulo Roberto Rodrigues. Do rural ao urbano: demografia, migrações e urbanização (1930-85). IN: GERTZ, René (dir.); GOLIN, Tau; BOEIRA, Nelson (Coord.). História Geral do Rio Grande do Sul: República: da revolução de 1930 a ditadura militar (1930-1985). Passo Fundo: Méritos, 2007.

SOLICITAÇÃO à Prefeitura Municipal de Canoas por parte da Sociedade Territorial São Carlos, 1951. Acervo UPHAM-Canoas.

SOUZA, Célia Ferraz de. Ideias em Circulação Sobre o Planejamento Urbano Integrado no RS na Década de 1960. IN: SOUZA, Célia Ferraz (Org.). Ideias em circulação na Construção das Cidades. Porto Alegre, 2014, p. 207-237. 
TATSCH, Ana Lúcia. Impactos da crise do início dos anos 80 sobre o mercado de trabalho: um estudo da Região Metropolitana de Porto Alegre. Indicadores Econômicos FEE: análise conjuntural, Porto Alegre, p. 194-210, nov. 1990.

TORRÃO FILHO, Amílcar. Bibliotheca Mundi: Livros de Viagem e Historiografia Brasileira como Espelhos da Nação. v. 42 (2011). Projeto História. Dossiê Viagens, viajantes e deslocamentos. jan./jun. 2011, p. 111-141.

UEDA, Vanda. $\mathrm{O}$ papel das redes técnicas: transportes, energia e telecomunicações. IN: GERTZ, René (dir.); GOLIN, Tau; BOEIRA, Nelson (coord.) História Geral do Rio Grande do Sul: República: da revolução de 1930 a ditadura militar (1930-1985). Passo Fundo: Méritos, 2007, p. 169-192.

UEKÖTTER, Frank Turning points in environmental history. German Historical Institut v. 37, 2005, p. 141-147.

VADELORGE, Löic. Des villes sans Histoire. Ethnologie Française, t. XXXVII, p. 21-30, 2003/2.

WOBETO, Jacó. Jacó Wobeto: depoimento [1994]. Entrevistador: Miguel Gaieski. Canoas/RS: 1994. Entrevista concedida ao Projeto Canoas: para lembrar quem somos - Bairro Rio Branco. Acervo do Museu Histórico La Salle-MAHLS.

WORSTER, Donald. Para fazer história ambiental. Revista Estudos Históricos. Rio de Janeiro, v.4, n.8, p.198-215.

RECEBIDO EM: 11/02/2019 APROVADO EM: 11/06/2020 